Goldschmidt 2021 Abstract

https://doi.org/10.7185/gold2021.8047

\section{Development of an extended matrix- matched calibration protocol for fast, high-resolution, quantitative chemical mapping of major and trace elements of polymineralic samples by laser- ablation coupled to time-of-flight- mass-spectrometry (LA-ICP-TOF- MS).}

\author{
DANY SAVARD ${ }^{1}$, SARAH A. S. DARE ${ }^{1}$, L.PAUL \\ BÉDARD $^{1}$, SARAH-JANE BARNES ${ }^{1}$ AND JOSEPH \\ PETRUS $^{2}$
}

${ }^{1}$ Universite du Quebec a Chicoutimi (UQAC)

${ }^{2}$ Laurentian University

Presenting Author: dany-d_savard@uqac.ca

In situ analysis conducted by LA-ICP-MS for the determination of trace elements in ore deposit studies provides precious information of chemical composition in a variety of minerals at the micrometer-scale. To date, most laser studies use quadrupole mass spectrometers (ICP-Q-MS) for the analysis of monomineral phases, using static spot (or line ablation), while chemical mapping can reveal important spatial (2D) information, such as growth zoning, exsolutions, micro-veins, microinclusions (Fig.1). However, peak jumping mode operation of ICP-Q-MS limits the acquisition speed and spatial resolution. Time-of-flight mass spectrometers (ICP-TOF-MS) can extract full mass range simultaneously at high rate $(33,000 \mathrm{~Hz})$, rendering the instrument attractive for routine analysis and allowing to take steps towards new research areas [1]. A new protocol was developed using a 193nm LA-system (RESOnetics, Applied Spectra) attached to an ICP-TOF-MS (TOFWERK) [2] to allow high-resolution quantitative mapping of polymineralic surfaces (Fig.1B-C). Simultaneous quantification of trace and major elements of different minerals (silicates, sulfides, oxides, zircon, apatite, calcite) within a single data processing, and without saturation of the ICP-TOF-MS detector, can be achieved by combining 7 reference materials of varied matrices (glasses, sulfide, apatite, zircon). Based on normalization of major elements without the use of an internal standard, a new data reduction scheme (DRS) was developed for IOLITE v4 software [3]. The DRS can recognize sulfide and calcite to apply appropriate Fe conversion factors or correct for "blind" element $\left(\mathrm{CO}_{2}\right)$, respectively. Using a $7 \mu \mathrm{m}$ beam in raster mode, a $1 \mathrm{~mm}^{2}$ area is covered in about 30 minutes.

Figure.1) Fe-Ti-oxide-apatite mineralisation (Sept-Iles Intrusion, Canada). [A] Reflected light microphotography. [B] LA-ICP-TOF-MS RGB composite image of $\mathrm{Cu}$ (red), $\mathrm{Pb}$ (blue) and $\mathrm{Ni}$ (green) revealing zonation in a pyrite grain in a late calcite-serpentine vein. Maximum intensity scales are $\mathrm{Cu}(500 \mathrm{ppm}), \mathrm{Pb}(20 \mathrm{ppm}), \mathrm{Ni}(150 \mathrm{ppm})$. [C] Normalized Fe(\%) distribution (LA-ICP-TOF-MS). Total map size is $2 \mathrm{~mm} x$ $0.7 \mathrm{~mm}$, resolution is $7 \mu \mathrm{m}(28,600$ pixels total $)$, acquisition time $\sim 50$ minutes.
[1] Sylvester, P.J. and Jackson, S.E. (2016), Elements 12, 307310. [2] Bussweiler, Y. et al. (2017), Spectroscopy 32, 14-20. [3] Paton et al. (2012), JAAS 26, 2508-2518.

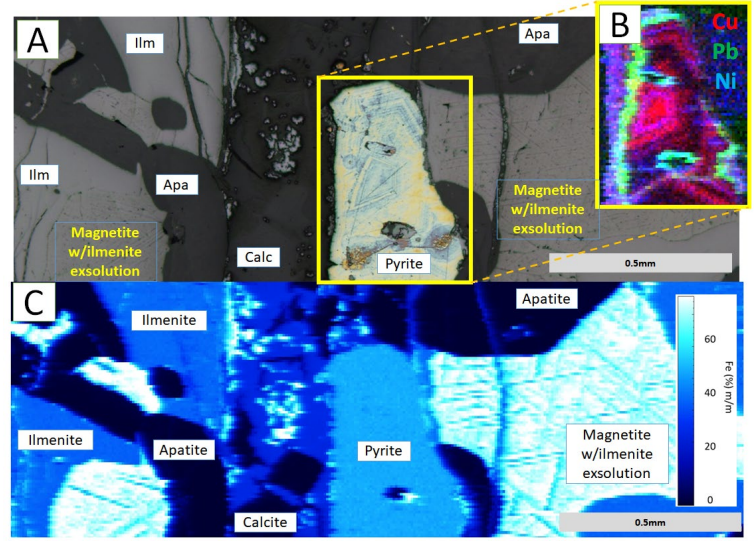

